\title{
Amphimerus bragai N. Sp. (Digenea: Opisthorchiidae), a Parasite of the Rodent Nectomys squamipes (Cricetidae) from Minas Gerais, Brazil
}

\author{
Antonio HA de Moraes Neto, Vernon E Thatcher*, Reinalda M Lanfredi**/+
}

\begin{abstract}
Departamento de Biologia, Instituto Oswaldo Cruz, Rio de Janeiro, RJ, Brasil *Instituto Nacional de Pesquisas da Amazônia, Manaus, AM, Brasil **Laboratório de Helmintologia, Programa de Biologia Celular e Parasitologia, Instituto de Biofísica Carlos Chagas Filho, CCS, Bloco G, Universidade Federal do Rio de Janeiro, Cidade Universitária, 21949-900 Rio de Janeiro, RJ, Brasil
\end{abstract}

\begin{abstract}
Amphimerus bragai n.sp. (Digenea, Opisthorchiidae) from the bile ducts of a rodent from the State of Minas Gerais, Brazil, Nectomys squamipes (Cricetidae), is described. The new species was studied by both light and scanning electron microscopy. A table is presented comparing the measurements of the new species with those of A. lancea (Diesing, 1850) and A. vallecaucensis Thatcher, 1970, parasites of dolphins and marsupials, respectively. The new species is similar in size and body form to A. vallecaucensis from which it differs in having a vitellarium that extends to the acetabulum while that of the former species are limited to the posterior one-third of the body. Additionally, the new species is from a rodent.
\end{abstract}

Key words: trematode - systematics - rodent parasite - opisthorchiid - Brazil

The genus Amphimerus Barker, 1911 is closely related to Opisthorchis and to Clonorchis from which it differs by having the vitellarium interrupted at the level of the ovary on either side. Species of these genera are thought to be transmitted by the ingestion of fish and most of the known definitive hosts are piscivorous or omnivorous birds and mammals. According to Yamaguti (1971), there are twenty species worldwide, nine from birds, ten from mammals and one from a freshwater turtle. Species of all three of these genera have potential for infecting man.

According to Thatcher $(1970,1993)$, three species of Amphimerus are known from Brazil and two of these are from mammals, namely: $A$. guayaquilensis (Rodríguez, Gómez Lince and Montalvan, 1949) from carnivores and marsupials and A. lancea (Diesing, 1850) from Amazonian dolphins, Sotalia tucuxi (Gervais, 1853). Additionally, Artigas and Pérez (1962) reported what they called A. pseudofelineus minutus from the bile ducts of the common opossum, Didelphis marsupialis (Linnaeus, 1758). Gomes (1979) described A. pseudofelineus from marsupials and con-

Financial support: PRONEX, FINEP, CNPq, Fundação Universitária José Bonifácio/UFRJ and Conselho de Ensino e Pós-Graduação/UFRJ.

${ }^{+}$Corresponding author. Fax: +55-21-280.8193. E-mail: reylanf@ibccf.biof.ufrj.br

Received 4 June 1997

Accepted 23 October 1997 sidered as a synonym of $A$. pseudofelineus minutus. The latter is almost certainly conspecific with $A$. guayaquilensis. Kohn et al. (1981) identified specimens found in the livers of the rodent Nectomys squamipes (Brants, 1827) as A. lancea from the State of Goiás, Brazil. This material has been reexamined and compared to a new collection from the same host. It has been determined that the worms from the two collections are conspecific and represent a new species which is described herein.

\section{MATERIALS AND METHODS}

The rodents were live-trapped and brought to the laboratory for examination. They were euthanized with ether and necropsied. The livers were teased apart with dissecting needles and the gall-bladders and common bile ducts were opened. This material was washed in $0.9 \%$ physiological saline solution and hand sedimented. The worms were then removed from the saline and fixed. For light microscopy, some specimens were fixed in AFA solution ( 93 parts of $70 \%$ alcohol, 5 parts of commercial formaldehyde and 2 parts of glacial acetic acid). They were then stained with Langeran's carmin, dehydrated in a graded alcohol series and mounted in Canada balsam without compression. All measurements are given in millimiters.

Specimens to be examined by scanning electron microscopy (SEM) were fixed in a solution containing $2.5 \%$ glutaraldehyde, $4 \%$ paraformaldehyde, $5 \mathrm{mM}$ calcium cloride in $0.1 \mathrm{M}$ cacodylate buffer (pH 7.2), at room temperature, washed with cacody- 
late buffer, dehydrated in ethanol, processed in a critical point dryer with $\mathrm{CO}_{2}$, sputter-coated with gold-paladium and examined in a JEOL JSM 25 SII scanning electron microscope operating at $15 \mathrm{kV}$.

All animals were maintained according to the Rules of Use and Care of Laboratory Animals of the Instituto de Biofísica Carlos Chagas Filho from the Universidade Federal do Rio de Janeiro, Rio de Janeiro, RJ, Brazil.

\section{DESCRIPTION}

Amphimerus bragai n. sp. (Figs 1-12)

Morphometrics: based on ten specimens.

With the characters of the genus. Body elongated, flattened, anterior end attenuated, expanded posterior to acetabulum, cirrus absent. Figs 1 and 2 show different stages of contraction. Body tegument as seen by SEM is rough (Figs 10,12) with whip-like structures more densely distributed near oral sucker (Fig. 9). Oral sucker subterminal, muscular, wider than long (Figs 1, 2, 3, 6, 7).
Prepharynx absent, muscular subspherical pharynx (Figs 1,2), short esophagus, intestine bifurcated, straight at half anterior portion, convoluted and wider at posterior portion, terminating at distance of 0.15-0.31 from posterior extremity (Figs 1,2). Round acetabulum, pre-equatorial (Figs 1, 2, 3, 4, 7), tegument rough (Fig. 11). Transversal genital aperture, bow shaped, immediately anterior and slightly dislocated to right of acetabulum (Figs 1a, 4,5 ). Seminal vesicle tubular, elongated, coiled, extending posteriorly from acetabulum (Fig. 1a). Testes diagonal, irregularly lobated, situated at posterior one third of body. Uterus curled, tubular. Ovary elongated or lobated. Vitellarium externolateral to ceca. Vitelline fields interrupted slightly anteriorly to ovary level. In most specimens vitellarium follicles not grouped, but randomly distributed. Seminal receptacle located next to ovary. Laurer's canal not observed. Excretory vesicle $\mathrm{Y}$ shaped with excretory pore at middle of posterior end (Figs 1, 2, 8). Oval eggs, operculated and double shelled (Fig. 2a).
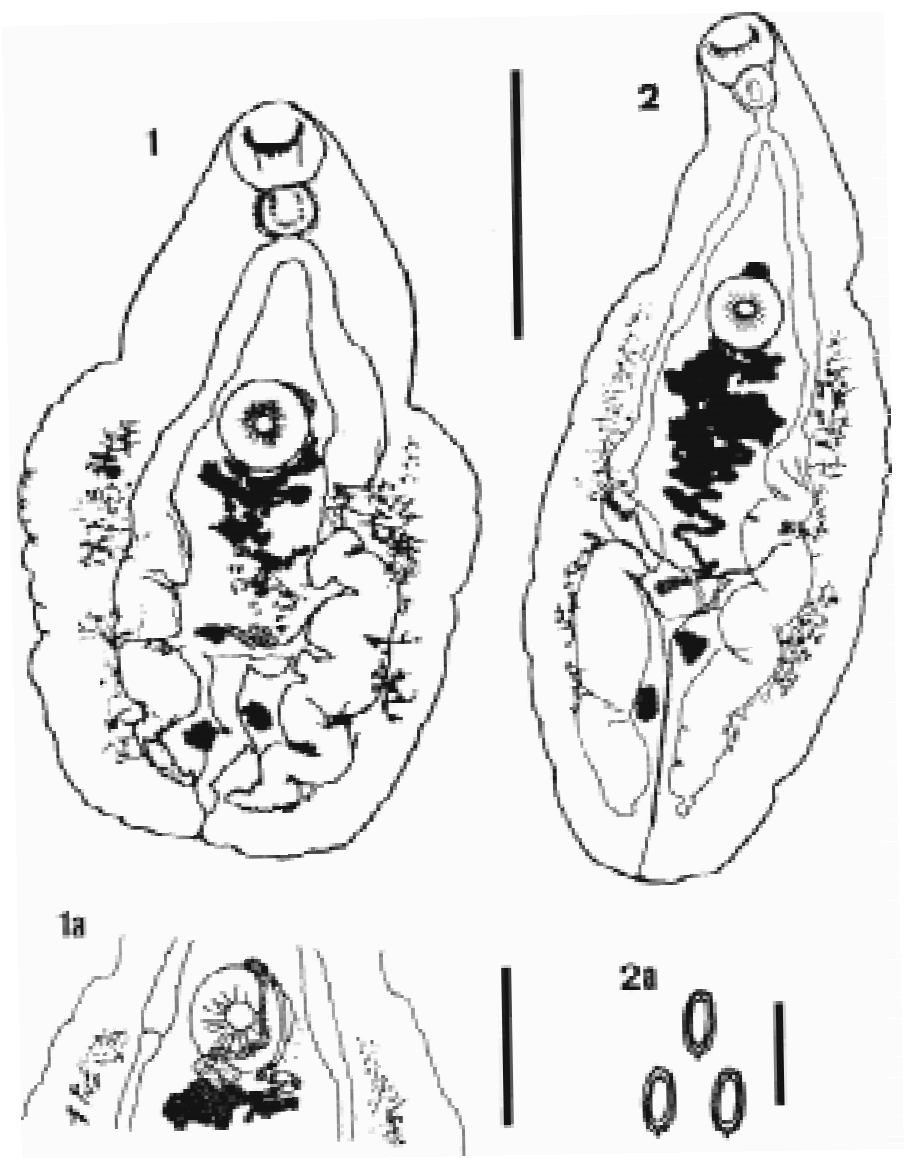

Amphimerus bragai n. sp. in ventral view. Fig. 1 more contracted than Fig. 2. Bar $=1 \mathrm{~mm}$. Fig. 1a: ventral view, terminal genitalia. $B a r=0.5 \mathrm{~mm}$. Fig. 2a: eggs. $\mathrm{Bar}=0.05 \mathrm{~mm}$. 


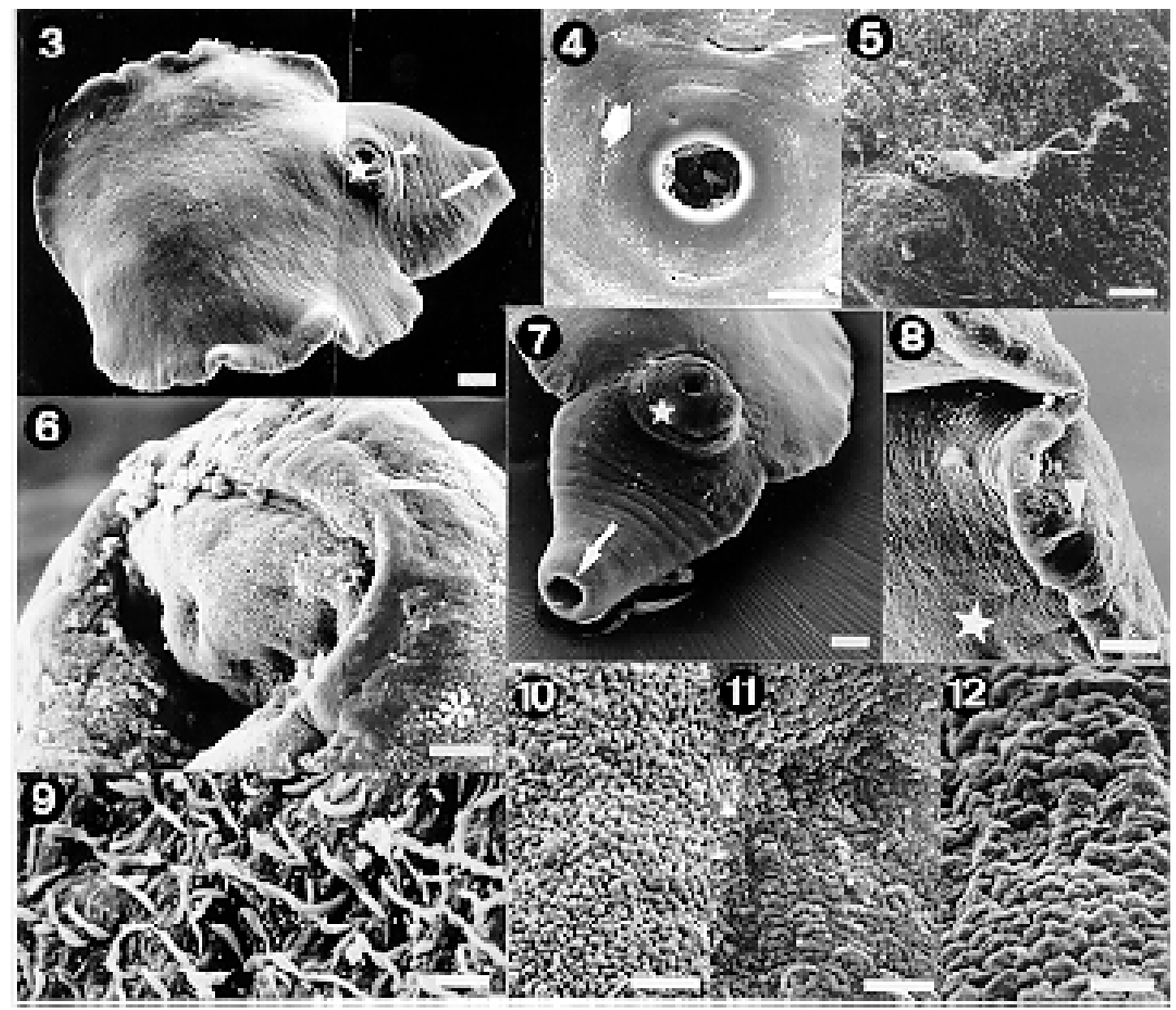

Scanning electron microscope views of surface features of Amphimerus bragai $\mathrm{n}$. sp. Fig. 3: ventral view, acetabulum (star), oral sucker (arrow), genital pore (arrowhead). Bar $=125 \mu \mathrm{m}$. Fig. 4: ventral view with acetabulum (large arrow) and genital pore (thin arrow). Bar $=50 \mu \mathrm{m}$. Fig. 5: genital pore with sperm. Bar $=10 \mu \mathrm{m}$. Fig. 6: details of oral sucker showing whip-like structures (asterisk). Bar $=20 \mu \mathrm{m}$. Fig. 7: en face view of oral sucker (arrow) and acetabulum (star). Bar $=125 \mu \mathrm{m}$. Fig. 8: lateral view, excretory pore (arrowhead) and ventral side (star). Bar $=50 \mu \mathrm{m}$. Fig. 9: tegument near the oral sucker showing elongated whip-like structures. Bar $=2.5 \mu \mathrm{m}$. Fig. 10: lateral view showing rugose tegument. Bar $=2.5 \mu \mathrm{m}$. Fig. 11: tegument on the acetabulum. Bar $=2.5 \mu \mathrm{m}$. Fig. 12: tegument on oral sucker. Bar $=2.0 \mu \mathrm{m}$.

Taxonomic summary

Type host: Nectomys squamipes (Brants, 1827): Cricetidae.

Site of infection: bile ducts.

Type locality: Lagoa Santa, Minas Gerais, Brazil (19³ $\left.38^{\prime} \mathrm{S}, 43^{\circ} 53^{\prime} \mathrm{W}\right)$.

Other known locality: Formosa, Goiás, Brazil.

Type material: holotype and one paratype: Helminthological Collection of the of the Oswaldo Cruz Institute (CHIOC) (collection no. $33645 \mathrm{a}-\mathrm{b}$ ). Etymology: the species is named in honor of the late Professor Ernani Braga, former Director of the Escola Nacional de Saúde Pública, Fundação Oswaldo Cruz, Rio de Janeiro, RJ, Brazil, and of the World Health Organization, Geneva, Switzerland.

\section{REMARKS}

A total of 47 specimens of Amphimerus were recovered from the two infected $N$. squamipes of Minas Gerais. These were studied in detail and compared with those from the same host species from Goiás which had been deposited in the collections of the Instituto Oswaldo Cruz by Kohn et al. (1981). In view of the close similarities in size, morphology and host, it was concluded that the two collections represent a single species.

This material was also compared with four paratypes of $A$. vallecaucensis and 15 voucher specimens of A. lancea all of which from the Helminthological Collection of the Instituto 
Nacional de Pesquisas da Amazônia.

The two collections of Amphimerus from the rodent, $N$. squamipes, contain worms that are closely similar in both size and morphology and are therefore thought to be conspecific. This species is similar in size to A. vallecaucensis described by Thatcher (1970) from a Colombian marsupial. The two species can be distinguished at a glance, however, since in the rodent form the vitellarium extends to the acetabulum while in A. vallecaucensis, the vitellarium is restricted to the posterior one-third of the body while the acetabulum is in the anterior one-third.

In the case of $A$. lancea, the specific name itself is taken from the Latin meaning a small spear or "lance". According to Diesing (1850) and Price (1932), the species is relatively large (to over 12 $\mathrm{mm}$ in length) and has the shape of a "lance" (that is the body tapers from the level of the acetabulum and terminates in a sharp point at the posterior extremity). Additionally, the edges of the body posterior to the acetabulum are serrated. The smallest ratio between the acetabulum and the oral sucker is $1: 1$ and the biggest is $1: 1.8$, the vitellarium consists of eight groups of follicles on each side of the body and according to figure 32 from Price (1932), after Weski (1900), they do not reach the acetabulum and the seminal vesicle is mostly pre-acetabular.

According to the figure of Diesing's description of A. lancea (1855, Plate II, Fig. 18) the vitellarium reaches the posterior margin of the acetabulum, the uterus is divided into branches, the intestinal ceca are rectilineal, the acetabulum is much larger than the oral sucker and occupies the whole width of the body, and the anterior part of the body (from the oral sucker to the acetabulum) is a longer and slender cone.

The new species (A. bragai) is small, bluntly, rounded at the posterior end (therefore does not look like a lance). It does not have serrated edges, the oral sucker and acetabulum are subequal, the vitellarium reaches the acetabulum, however the follicles are not grouped but randomly distributed, and the genital pore is anterior and dislocated to the right of the acetabulum. The ratio between the acetabulum and the oral sucker varied from 1:1 to $1: 1.2$. The uterus is a curled tube, the intestinal ceca are convoluted and become wider at the posterior region, the acetabulum is not as wide as the body, and the anterior part of the body is a wide cone.

A. pseudofelineus (Ward, 1901) of marsupials from Belém, Pará, Brazil as described by Gomes (1979) has a much longer uterus, the intestinal ceca are slender and rectilineal, and the vitellarium does not reach the acetabulum when compared to A. bragai. The same differences are seen among the new species and Thatcher's (1970) description of A. neotropicalis Caballero, Montero Gei, and Caballero, 1963 and A. guayaquilensis (Rodríguez, Gómez Lince, and Montalvan, 1949) of marsupials from Colombia.

A. pricei Foster, 1939 of a marsupial from Panama differs from A. bragai since it presents a very long tubular and folded uterus, and the vitellarium is divided into different number of groups of follicles on both sides of the body.

A. bragai n. sp. as seen by SEM is wholy covered by a rough tegument with whip-like structures irregularly distributed on the surface, and more densely near the oral sucker. Price (1932) described the tegument of A. lancea as "frequently covered wholy or in part with small spines". Other authors described by SEM the tegument of digenetic trematodes. Ahmad et al. (1988) observed that Fasciola gigantica Cobbold, 1885 from Indian buffalos presented spines with or without dentations and oral and ventral suckers devoid of spines or papillae. Cohen et al. (1995) studied the tegument of Prosorhynchoides arcuatus (Linton, 1900) of fish from Rio de Janeiro, Brazil and observed scale like and serrated spines and uniciliated sensory papillae distributed over the body surface. Pekkarinen and Ching (1994) compared the tegument of two species of Lacunovermis, and two species of Gymnophallus of clams from the Pacific Ocean and the Baltic Sea. These authors observed that the two genera were covered with spines that differ in shape and size and presented papillae surrounding the oral sucker. Ahmad et al. (1988) described that Gigantocotyle explanatum Näsmark, 1937 from Indian buffalos presented domed and rosette shaped papillae and tegumental annulations over the body surface. Baptista-Farias et al. (1992) reported that the tegument of Balanorchis anastrophus Fischoeder, 1901 of cattle from Pará, Brazil presented tegumental ridges, three crowns of tentacles and dome-shaped papillae surrounding the oral sucker, and verrucous papillae surrounding the ventral sucker. Kohn et al. (1997) described that Prosthenhystera obesa (Diesing, 1850) of fish from Paraná River, Brazil presented aciliated papillae more evident around the oral sucker and not observed around the acetabulum. Our description of the tegument is different from all of these.

All the differences lead us to conclude that the specimens from rodents that are herein described are a new species named A. bragai. The finding of an opisthorchiid in a rodent is surprising since in all the known life cycles in the family fish transmit the infection to the definitive host. It would appear that $N$. squamipes must feed on fish at least occasionally. 
TABLE

Measurements of Amphimerus bragai n. sp., A. lancea (Kohn et al., 1981), A. vallecaucensis Thatcher, 1970 and A. lancea Price, 1932

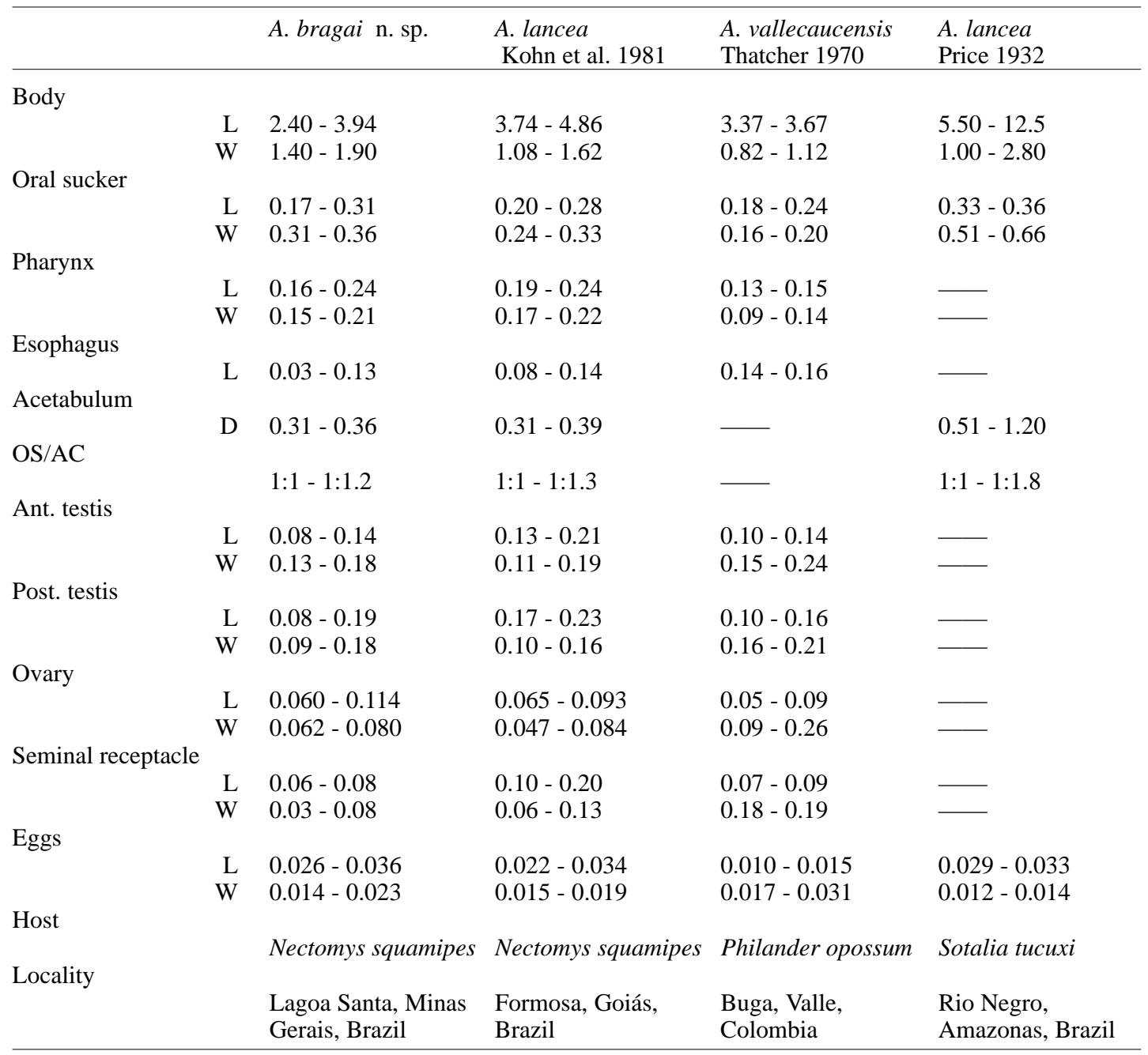

All sizes are in mm. L: length; W: width; D: diameter; OS/AC: oral sucker-acetabulum ratio.

\section{ACKNOWLEDGMENTS}

To Drs Anna Kohn and Dely Noronha for the loan of specimens from the Helminthological Collections of the Oswaldo Cruz Institute. To Dr Márcia Attias, Laboratório de Ultraestrutura Celular Hertha Meyer, Instituto de Biofísica Carlos Chagas Filho, Universidade Federal do Rio de Janeiro for the orientation in the use of the scanner and image processing.

\section{REFERENCES}

Ahmad M, Nizami WA, Hanna REB 1988. Topographical studies of two digenetic trematodes of buffalo by scanning electron microscopy. Zool Anz 220: 59-64.

Artigas PT, Pérez MD 1962. Considerações sobre Opisthorchis pricei Foster, 1939, O. quayaquilensis Rodrigues, Gomez e Montalvan, 1949 e $O$. pseudofelineus Ward, 1901 - Descrição de Amphimerus pseudofelineus minimus, n. sub. sp. Mem Inst Butantan 30: 157-166.

Baptista-Farias MFD, Kohn A, Miguens FC 1992. Report of Balanorchis anastrophus in Pará State with surface topography by scanning electron microscopy. Mem Inst Oswaldo Cruz 87: 31-35.

Cohen SC, Kohn A, Barth OM 1995. Scanning electron microscopic study of Prosorhynchoides arcuatus (Linton, 1900) (Bucephalidae: Digenea). Mem Inst Oswaldo Cruz 90: 25-32.

Diesing KM 1850. Systema Helminthum I, 679 pp.

Diesing KM 1855. Neunzehn arten von trematoden. Denks Akad Wissen Wien Math Naturw KI 10: 5970.

Gomes DC 1979. Contribuição ao conhecimento dos helmintos parasitos de marsupiais no Brasil, da 
Coleção Helmintológica do Instituto Oswaldo Cruz - Trematoda. Atas Soc Biol 20: 33-43.

Kohn A, Fernandes BMM, Pinto RM, Mello DA 1981. Maritremopsis mariettavogeae sp. n. (Trematoda, Microphallidae) and Amphimerus lancea (Trematoda, Opisthorchiidae) parasites of Nectomys squamipes (Rodentia) in Brazil. Mem Inst Oswaldo Cruz 76: 393-396.

Kohn A, Fernandes BMM, Baptista-Farias, MFD 1997. Redescription of Prosthenhystera obesa (Diesing, 1850) (Callodistomidae, Digenea) with new host records and data on morphological variability. Mem Inst Oswaldo Cruz 92: 171-179.

Pekkarinen M, Ching HL 1994. Comparisons of Gymnophallid digeneans from North Pacific and
Baltic clams, Macoma balthica (Bivalvia). J Parasitol 80: 630-636.

Price EW 1932. Trematode parasites of marine mammals. Proc US Nat Mus 81: 1-67.

Thatcher VE 1970. The genus Amphimerus Baker, 1911 (Trematoda: Opisthorchiidae) in Colombia with the description of a new species. Proc Helminthol Soc Washington 37: 207-211.

Thatcher VE 1993. Trematódeos Neotropicais. INPA/ FUA, Manaus, AM, Brasil, $553 \mathrm{pp}$.

Weski O 1900. Mitteilungen über Distomum lancea Dies. Centralb für Bakt, Parasit und Infekt, Abt. 1, 27: 579-583.

Yamaguti S 1971. Synopsis of the Digenetic Trematodes of Vertebrates, 2 vol., Keigaku Co., Tokyo, 1074 pp. 